\title{
Stage IIIA Gestational Trophoblastic Tumor AJCC v7
}

National Cancer Institute

\section{Source}

National Cancer Institute. Stage IIIA Gestational Trophoblastic Tumor A/CC V7. NCI

Thesaurus. Code C87157.

Stage IIIA includes: Any T, M1a, Risk factors: low risk. M1a: Lung metastasis. (AJCC 7th ed.) 